\title{
An hour-specific transcutaneous bilirubin nomogram for Mongolian neonates
}

\author{
Moe Akahira-Azuma $^{1} \cdot$ Naohiro Yonemoto $^{2} \cdot$ Rintaro Mori $^{3} \cdot$ Shinichi Hosokawa $^{1}$. \\ Takeji Matsushita $^{1}$ - Khulan Sukhbat ${ }^{4}$ - Gerelmaa Nansal ${ }^{4}$. \\ Bayasgalantai Bavuusuren ${ }^{4}$. Enkhtur Shonkhuuz ${ }^{4}$
}

Received: 11 February 2015 /Revised: 29 March 2015 / Accepted: 1 April 2015 /Published online: 14 April 2015

(C) The Author(s) 2015. This article is published with open access at Springerlink.com

\begin{abstract}
Transcutaneous bilirubin (TcB) nomograms have been developed for different populations. However, the TcB level, rate of rise and peak varies among countries and ethnicities. The aim of this study was to establish an hour-specific TcB nomogram for healthy term and late preterm Mongolian neonates during the first $144 \mathrm{~h}$ after birth. A total of $5084 \mathrm{TcB}$ measurements from 1297 healthy neonates (gestational age $\geq 35$ weeks, birth weight $\geq 2000 \mathrm{~g}$ ) were obtained from October 2012 to October 2013. All measurements were performed using the Jaundice Meter, the JM-103 at 6 to 144 postnatal hours. Mongolian infants had the following characteristics: $27.1 \%$ were delivered by cesarean section, $17.8 \%$ had a birth weight $>4000 \mathrm{~g}$, and $>90 \%$ were being breastfed. TcB percentiles for each designated time point were calculated for the development of an hour-specific nomogram. TcB levels increased most rapidly in the first $24 \mathrm{~h}$ and less rapidly from 24 to $78 \mathrm{~h}$, reaching a plateau after $78 \mathrm{~h}$ for the 50 th percentile. TcB
\end{abstract}

Communicated by Patrick Van Reempts

Moe Akahira-Azuma

nth3son@yahoo.co.jp

Naohiro Yonemoto

nyonemoto@gmail.com

Rintaro Mori

rintaromori@gmail.com

Shinichi Hosokawa

shosokaw@hosp.ncgm.go.jp

Takeji Matsushita

tmatsush@hosp.ncgm.go.jp

Khulan Sukhbat

hulan_1213@yahoo.com

Gerelmaa Nansal

ngerelmaa@yahoo.com levels of Mongolian neonates for each time point were higher than those of previous studies.

Conclusion: The higher values of the TcB nomogram for Mongolian neonates may be due to their Asian ethnicity and exclusive breastfeeding.

What is Known:

- TcB nomograms for neonatal jaundice screening have been established for many countries and ethnicities. The pattern of the TcB nomogram varies by country and ethnicity.

What is New:

- A TcB nomogram for neonates of Mongolian ethnicity at 6-144 postnatal hours was created and it had higher values than those in previous studies.

Keywords Neonatal hyperbilirubinemia $\cdot$ Transcutaneous bilirubin $\cdot$ Hour-specific nomogram $\cdot$ Mongolian

Bayasgalantai Bavuusuren

bayasgalantai.b@gmail.com

Enkhtur Shonkhuuz

enkhtur_mgl@yahoo.com

1 Department of Pediatrics, National Center for Global Health and Medicine, 1-21-1 Toyama, Shinjuku-ku, Tokyo 162-8655, Japan

2 Department of Neuropsychopharmacology, National Institute of Mental Health, National Center of Neurology and Psychiatry, 4-1-1 Ogawahigashimachi, Kodaira 187-8553, Tokyo, Japan

3 Department of Health Policy, National Center for Child Health and Development, 2-10-1 Okura, Setagaya-ku 157-8535, Tokyo, Japan

4 National Center for Maternal and Child Health of Mongolia, Huvisgalchid Street, Bayangol District, Ulaanbaatar 16060, Mongolia 


$\begin{array}{ll}\text { Abbreviations } \\ \text { AAP } & \text { American Academy of Pediatrics } \\ \text { G6PD } & \text { Glucose-6 pyruvate deficiency } \\ \text { GA } & \text { Gestational age } \\ \text { TcB } & \text { Transcutaneous bilirubin } \\ \text { TSB } & \text { Total serum bilirubin }\end{array}$

\section{Introduction}

Neonatal hyperbilirubinemia and neurological sequelae resulting from kernicterus pose a serious medical burden in both developing and developed countries [13, 15, 16, 23]. However, severe hyperbilirubinemia in the newborn is preventable through appropriate follow-up, diagnosis, and treatment, such as phototherapy and exchange transfusions [8, 9, 13, 23]. The American Academy of Pediatrics (AAP) recommends that all neonates undergo total serum bilirubin (TSB) or transcutaneous bilirubin (TcB) measurements at least once before hospital discharge to assess their risk of hyperbilirubinemia $[2,17]$.

TcB nomogram is a useful tool for neonatal hyperbilirubinemia screening [10]. However, the TcB value, rate of rise and peak varies with country and ethnicity [5], suggesting that each country and ethnic group has specific risk factors for hyperbilirubinemia. Few studies on the TcB nomogram have been done for Mongolian neonates in a resource-limiting setting [1].

The aim of this study was to create an hour-specific TcB nomogram for healthy Mongolian neonates, which was achieved by obtaining TcB measurements in the first $144 \mathrm{~h}$ after birth.

\section{Methods}

\section{Patients}

This was a prospective cohort study at the National Center for Maternal and Child Health (NCMCH), a tertiary care hospital in Ulaanbaatar, Mongolia. Neonates who were eligible for enrollment were healthy newborns $\geq 35$ weeks of gestation with a birth weight $\geq 2000 \mathrm{~g}$ who were delivered in the hospital on a weekday (from Monday to Friday morning) and whose address were in the Bayangol district. Exclusion criteria included the following: infants with birth asphyxia, respiratory distress, NICU admission, congenital infection, $\mathrm{Rh}$ isoimmunization, jaundice within $24 \mathrm{~h}$ of birth, skin infection, congenital spinal anomaly, those with no TcB measurement, and cases with missing information. The study was carried out from October 15, 2012 to October 4, 2013 but was temporarily suspended between June 28 and August 2, 2013 when the maternity unit was closed for renovation. Perinatal information on the mother and infant were extracted from their medical charts including sex, gestational age, birth weight, mode of delivery, duration of hospitalization, maternal age, parity, gravidity, maternal blood type, family history of siblings, and feeding type before and after discharge.

This study was approved by the NCMCH ethics committee in Mongolia and the National Center for Global Health and Medicine (NCGM) human investigation ethics committee in Japan, in accordance with the Declaration of Helsinki. Informed consent was obtained from all individual participants (mothers of the infants) included in the study.

\section{Measurements}

TcB measurements were performed between 9 am and $5 \mathrm{pm}$ twice daily (once in the morning and once in evening) from Monday to Friday. The Jaundice Meter JM-103 (Konica Minolta, Osaka, Japan) was used by properly trained pediatricians or a research technician to measure TcB. The operation of the JM-103 and its measurement technique have been described previously [1]. Briefly, TcB levels were measured at the forehead and at the midsternum three times at each site, and the median value was defined as the $\mathrm{TcB}$ at each measurement site. The highest value of two sites was used as the TcB for each infant. Because NCMCH applies a discharge policy of $\geq 48 \mathrm{~h}$ for vaginally delivered infants and $\geq 72 \mathrm{~h}$ for those delivered by cesarean section, the parents were advised to return to the outpatient clinic for follow-up measurements. Enrolled neonates returned for a follow-up visit between days 3-6 or earlier if the parents noticed worsening jaundice in their child. Parents who did not bring their child for the visit were reminded by telephone. An enrollment number was given to each neonate and recorded in a log book to identify the study neonate during the visit. TcB values were recorded on a flow sheet designed for the study and attached to the signed informed consent form in the medical record of each infant.

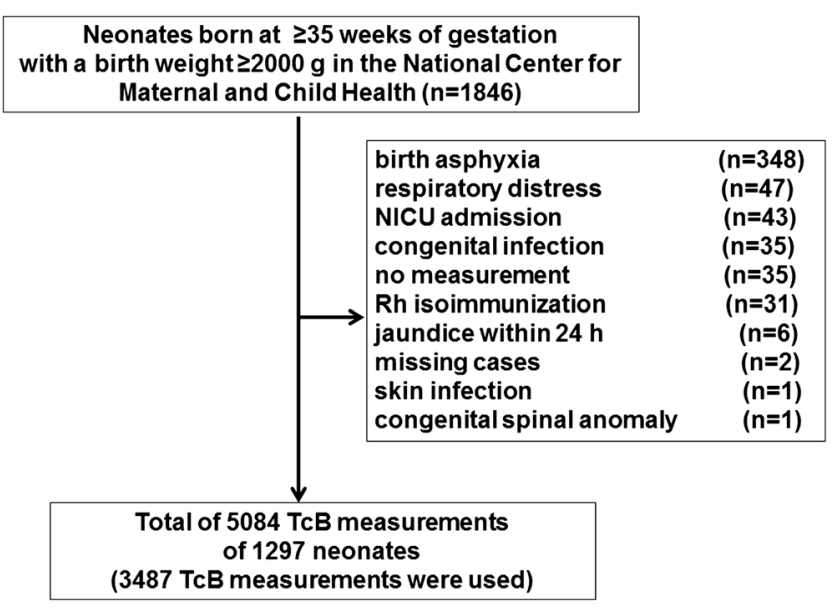

Fig. 1 Study flow 
TcB measurements obtained at $6 \pm 2 \mathrm{~h}$ intervals up to $144 \mathrm{~h}$ were examined $[12,18]$. TcB measurements not taken between these time measurements were omitted from analysis.
The decision regarding the need for phototherapy was made by the attending pediatrician based on TSB levels, in accordance with NCMCH's protocol and/or AAP guidelines [2]. If
Table 1 Characteristics of the enrolled neonates and their mothers

\begin{tabular}{|c|c|c|c|}
\hline Characteristic & & $n=1297$ & $(\%)$ \\
\hline \multirow[t]{2}{*}{ 1. Sex } & Male & 662 & $(51.0)$ \\
\hline & Female & 635 & $(49.0)$ \\
\hline \multirow[t]{3}{*}{ 2. Gestational age } & $35-36$ weeks & 16 & $(1.2)$ \\
\hline & $37-40$ week & 1230 & $(94.9)$ \\
\hline & 41-42 weeks & 51 & $(3.9)$ \\
\hline \multirow[t]{4}{*}{ 3. Birth weight } & $2000-2999 \mathrm{~g}$ & 92 & $(7.1)$ \\
\hline & $3000-3999 \mathrm{~g}$ & 975 & $(75.1)$ \\
\hline & $4000-4999 \mathrm{~g}$ & 228 & $(17.6)$ \\
\hline & $>5000 \mathrm{~g}$ & 2 & $(0.2)$ \\
\hline \multirow[t]{2}{*}{ 4. Mode of delivery } & Vaginal & 945 & $(72.9)$ \\
\hline & Cesarean section & 352 & $(27.1)$ \\
\hline \multirow[t]{3}{*}{ 5. Duration of hospitalization } & $1-2$ day (s) & 907 & $(69.9)$ \\
\hline & $3-4$ days & 355 & $(27.4)$ \\
\hline & 5-7 days & 35 & $(2.7)$ \\
\hline \multirow[t]{3}{*}{ 6. Maternal age } & 15-24 years old & 293 & $(22.6)$ \\
\hline & 25-34 years old & 748 & $(57.7)$ \\
\hline & $35-45$ years old & 256 & $(19.7)$ \\
\hline \multirow[t]{5}{*}{ 7. Parity } & 1 & 320 & $(24.7)$ \\
\hline & 2 & 411 & $(31.7)$ \\
\hline & 3 & 258 & (19.9) \\
\hline & 4 & 169 & $(13.0)$ \\
\hline & 5 to 9 & 139 & $(10.7)$ \\
\hline \multirow[t]{5}{*}{ 8. Gravidity } & 1 & 451 & $(34.8)$ \\
\hline & 2 & 541 & $(41.7)$ \\
\hline & 3 & 230 & $(17.7)$ \\
\hline & 4 & 60 & $(4.6)$ \\
\hline & 5 to 9 & 15 & $(1.2)$ \\
\hline \multirow[t]{6}{*}{ 9. Maternal blood type } & $\mathrm{O}$ & 366 & $(28.2)$ \\
\hline & A & 347 & $(26.8)$ \\
\hline & $\mathrm{B}$ & 456 & $(35.2)$ \\
\hline & $\mathrm{AB}$ & 116 & $(8.9)$ \\
\hline & Unknown & 11 & $(0.8)$ \\
\hline & No description & 1 & $(0.1)$ \\
\hline \multirow[t]{4}{*}{ 10. Family history of siblings } & First baby & 446 & $(34.4)$ \\
\hline & Phototherapy & 161 & $(12.4)$ \\
\hline & Exchange transfusion & 2 & $(0.2)$ \\
\hline & No jaundice & 688 & $(53.0)$ \\
\hline \multirow[t]{3}{*}{ 11. Feeding (before discharge) } & Breastfeeding & 1264 & $(97.4)$ \\
\hline & Formula & 3 & $(0.2)$ \\
\hline & Mixed & 30 & $(2.3)$ \\
\hline \multirow[t]{5}{*}{ 12. Feeding (follow-up visit) } & No follow-up visit & 160 & \\
\hline & Attended follow-up visit & 1137 & \\
\hline & Breastfeeding & 1025 & $(90.1)$ \\
\hline & Formula & 1 & $(0.1)$ \\
\hline & Mixed & 111 & $(9.8)$ \\
\hline
\end{tabular}


TcB values were obtained, measurement values obtained after the initiation of phototherapy were excluded from analysis.

The characteristics of mothers and children are presented as percentages for binary and categorical data, and as means and standard deviations for continuous data. The data analysis was performed by using SPSS 15.0 for Windows (SPSS, Chicago, IL).

TcB percentiles (95th, 90th, 75th, 50th, 25th, 10th, and 5th percentiles) were calculated for each designated time. A TcB nomogram with smoothed percentile curves for the period 6144 postnatal hours was prepared using Microsoft Excel 2010 (Microsoft, Redmond, WA).

\section{Results}

Of 1846 live births in NCMCH during the study period, 549 neonates did not meet the enrollment criteria (Fig. 1), resulting in 1297 healthy term and late-preterm neonates from whom $5084 \mathrm{TcB}$ measurements were obtained. Among these TcB measurements, 3487 that were taken at the designated time were used for analysis. Of the 1297 enrolled neonates, 1137 $(87.7 \%)$ returned for the follow-up visit after hospital discharge.

Demographic and background data of mothers and neonates are summarized in Table 1. Of note, all neonates were Mongolian, $27.1 \%$ were delivered by a cesarean section, $\geq 90 \%$ were breastfed, and $17.8 \%$ had a birth weight $\geq 4000 \mathrm{~g}$. Regarding the family history of jaundice, 851 of 1297 enrolled infants had siblings and 163 of 851 siblings $(19.2 \%)$ had a history of treatment for jaundice according to an interview with the mother. Details of the jaundice could not be obtained to clarify the etiology of jaundice.

A TcB nomogram with smoothed percentile curves (95th, 90th, 75th, 50th, 25th, 10th, and 5th percentiles) for the time period 6-144 postnatal hours is presented in Fig. 2. The numbers of $\mathrm{TcB}$ measurements are shown for each time point. $\mathrm{TcB}$ levels increased in a linear fashion most rapidly in the first $24 \mathrm{~h}$ and less rapidly from 24 to $78 \mathrm{~h}$, reaching a plateau after $78 \mathrm{~h}$ for the 50th percentile.

\section{Discussion}

We created an hour-specific TcB nomogram for the first $144 \mathrm{~h}$ after birth for Mongolian healthy term and late preterm neonates. The characteristics of this group of Mongolian neonates included delivery by cesarean section in $26.9 \%$ of cases and exclusive breastfeeding in $>90 \%$. The TcB values and rate of rise at each designated time point resulted in a TcB nomogram with higher values than those reported for other countries and ethnicities in previous studies. This result indicates that this

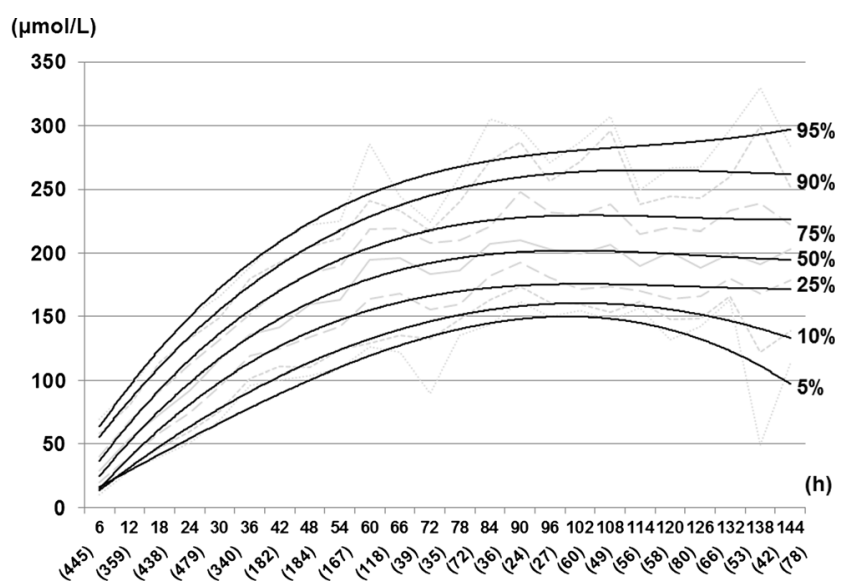

Fig. 2 An hour-specific TcB nomogram for Mongolian neonates with smoothed curves for the 5th, 10th, 25th, 50th, 75th, 90th, and 95th percentiles. Numbers in parentheses indicate the number of TcB measurements at each time point

group might have risk factors and a higher likelihood of developing neonatal hyperbilirubinemia.

Many TcB nomogram studies have been performed in North America, Europe, and Asia in different groups [3, 6, $7,11,12,14,18,19,21,25,28]$ since the second generation of the TcB meter became available. The risk factors of hyperbilirubinemia were determined to be Asian ethnicity, exclusive breastfeeding, weight loss, and a sibling with neonatal jaundice [17]. In a North American study investigating an hour-specific TcB nomogram in the first $96 \mathrm{~h}$ using the JM103 to measure levels in 3984 neonates, $73.1 \%$ were Caucasian, $45.1 \%$ were delivered by cesarean section, and $66.2 \%$ were breastfed [18]. TcB nomogram for Mongolian neonates showed much higher values than the North American nomogram at each time point. This might be due to the predominant Caucasian ethnicity of the study group [22]. In a study on infants of Asian ethnicity, a TcB nomogram was developed using JM-103 measurements taken from 6035 Chinese infants [28]. These Chinese infants were delivered by cesarean section in $55.5 \%$ of cases, $25.1 \%$ were breastfed, and $9.4 \%$ had a birth weight $>4000 \mathrm{~g}$. In contrast, our study of Mongolian neonates showed higher $\mathrm{TcB}$ values at each time point, suggesting that exclusive breastfeeding might have contributed to this result [4]. A recent study on the influence of dehydration on body weight loss at $72 \mathrm{~h}$ after birth in Taiwan revealed the optimum body weight loss cutoff points for predicting hyperbilirubinemia [27]. Unfortunately, the body weights on each day of TcB measurement were not determined in our study. Therefore, it remains unclear whether the acceleration of hyperbilirubinemia of Mongolian neonates is caused by exclusive breastfeeding itself or by dehydration secondary to inappropriate breastfeeding.

This prospective cohort study was a tertiary hospital-based study that enrolled neonates from one district, and TcB measurements were done either in the maternity unit or in the 
outpatient clinic [26]. Our study method for creating a TcB nomogram is practical and can be applied in countries with limited resources. This encourages resource-limited countries to create country- and ethnic-specific TcB nomograms.

This study has several limitations. First, there were insufficient numbers of $\mathrm{TcB}$ measurements at the follow-up visit on day 3-6, only one to two measurements. Second, the designated times for $\mathrm{TcB}$ measurements were difficult to establish, leading to the omission of a certain number of TcB measurements. However, it was impossible to fix a designated TcB measurement time for each neonate in ordinary practice. Third, the glucose-6-phosphate dehydrogenase (G6PD) and direct Coombs test are not routinely performed in prenatal care screening in Mongolia so G6PD deficiency and ABO incompatibility could not be ruled out in this group. Fourth, cephalohematoma, a risk factor for hyperbilirubinemia, might be increased, considering the high percentage of vaginal deliveries and heavy infants ( $17.8 \%$ had birth weight $>4000 \mathrm{~g})$ $[20,24]$. Although cephalohematoma should have been identified as a risk factor, this does not affect the validity of the nomogram. Fifth, because infants with significant hyperbilirubinemia were referred to the hospital for further work-up and treatment and were later excluded from the study, the TcB measurements and curves we report here might be lower than the actual $\mathrm{TcB}$ values.

The findings in this study contribute to improving appropriate diagnosis and treatment of neonatal hyperbilirubinemia, and might reduce the incidence of neurological impairment in this high-risk ethnic group.

\section{Conclusion}

We provide data on $\mathrm{TcB}$ levels for the first 144 postnatal hours that were derived from a group of Mongolian term and late preterm neonates. The higher values of the TcB nomogram derived from Mongolian neonates may be due to their Asian ethnicity and exclusive breastfeeding.

Acknowledgments We thank Dr. Gerentuya Dashzeveg for performing $\mathrm{TcB}$ measurements and maternity unit staff for their collaboration in this research project.

Role of the funding source This work was supported in part by Grantsin-Aid for Research from the National Center for Global Health and Medicine (24A-1, 26A-201 and 27A-1404).

Conflict of interest The authors declare that they have no conflicts of interest.

Compliance with ethical standards This study was approved by the National Center for Maternal and Child Health ethics committee in Mongolia and the National Center for Global Health and Medicine human investigation ethics committee in Japan. All procedures performed in studies involving human participants were in accordance with the ethical standards of the institutional and/or national research committee and with the 1964 Helsinki declaration and its later amendments or comparable ethical standards. A written informed consent was obtained from all mothers.

Authors' contributions MAA conceptualized and designed the study, carried out the initial analyses, drafted the initial manuscript, and approved the final manuscript as submitted. NY conceptualized and advised on the analysis, reviewed the manuscript, and approved the final manuscript as submitted. RM conceptualized and reviewed the manuscript, and approved the final manuscript as submitted. SH, TM reviewed the manuscript, and approved the final manuscript as submitted. KS, GN designed the data collection instruments, coordinated and reviewed the manuscript, and approved the final manuscript as submitted. BB designed the data collection instruments, coordinated and supervised data collection, reviewed the manuscript, and approved the final manuscript as submitted. ES reviewed the manuscript and approved the final manuscript as submitted.

Open Access This article is distributed under the terms of the Creative Commons Attribution 4.0 International License (http:// creativecommons.org/licenses/by/4.0/), which permits unrestricted use, distribution, and reproduction in any medium, provided you give appropriate credit to the original author(s) and the source, provide a link to the Creative Commons license, and indicate if changes were made.

\section{References}

1. Akahira-Azuma M, Yonemoto N, Ganzorig B, Mori R, Hosokawa S, Matsushita T, Bavuusuren B, Shonkhuuz E (2013) Validation of a transcutaneous bilirubin meter in Mongolian neonates: comparison with total serum bilirubin. BMC Pediatr 13:151. doi:10.1186/ 1471-2431-13-151

2. American Academy of Pediatrics (2004) Management of hyperbilirubinemia in the newborn infants 35 or more weeks of gestation. Pediatrics 114:297-316

3. Bental YA, Shiff Y, Dorsht N, Litig E, Tuval L, Mimouni FB (2009) Bhutani-based nomograms for the prediction of significant hyperbilirubinaemia using transcutaneous measurements of bilirubin. Acta Paediatr 98:1902-8. doi:10.1111/j.1651-2227.2009. 01385.X

4. Chen YJ, Chen WC, Chen CM (2012) Risk factors for hyperbilirubinemia in breastfed term neonates. Eur J Pediatr 171: $167-171$

5. De Luca D, Jackson GL, Tridente A, Carnielli VP, Engle WD (2009) Transcutaneous bilirubin nomograms: a systematic review of population differences and analysis of bilirubin kinetics. Arch Pediatr Adolesc Med 163:1054-1059

6. De Luca D, Jackson GL, Engle WL (2013) Chapter 5. Transucutaneous bilirubin nomograms. In: De Luca D, Engle WL, Jackson GL (eds) Transcutaneous bilirubinometry. Nova, New York, pp 67-89

7. De Luca D, Romagnoli C, Tiberi E, Zuppa AA, Zecca E (2008) Skin bilirubin nomogram for the first $96 \mathrm{~h}$ of life in a European normal healthy newborn population, obtained with multiwavelength transcutaneous bilirubinometry. Acta Paediatr 97:146-50. doi:10.1111/j.1651-2227.2007.00622.x

8. Dennery PA, Seidman D, Stevenson DK (2001) Neonatal hyperbilirubinemia. N Engl J Med 344:581-590

9. Dijk PH, Hulzebos C (2012) An evidence-based view on hyperbilirubinemia. Acta Paediatr 101(Suppl 464):3-10 
10. Engle WD, Jackson GL, Engle NG (2014) Transcutaneous bilirubinometry. Semin Perinatol 38:438-451. doi:10.1053/j. semperi.2014.08.007

11. Engle WD, Lai S, Ahmad N, Manning MD, Jackson GL (2009) An hour-specific nomogram for transcutaneous bilirubin values in term and late preterm Hispanic neonates. Am J Perinatol 26:425-30. doi: 10.1055/s-0029-1214238

12. Fouzas S, Mantagou L, Skylogianni E, Mantagos S, Varvarigou A (2010) Transcutaneous bilirubin levels for the first 120 postnatal hours in healthy neonates. Pediatrics $125:$ e52-7. doi:10.1542/ peds. 2009-0403

13. Kaplan M, Bromiker R, Hammerman C (2011) Severe neonatal hyperbilirubinemia and kernicterus: are these still problems in the third millennium? Neonatology 100:354-362. doi:10.1159/ 000330055

14. Kuboi T, Kusaka T, Kawada K, Koyano K, Nakamura S, Okubo K, Yasuda S, Isobe K, Itoh S (2013) Hour-specific nomogram for transcutaneous bilirubin in Japanese neonates. Pediatr Int 55:60811. doi:10.1111/ped.12149

15. Kuzniewicz MW, Wickremasinghe AC, Wu YW, McCulloch CE, Walsh EM, Wi S, Newman TB (2014) Incidence, etiology, and outcomes of hazardous hyperbilirubinemia in newborns. Pediatrics 134:504-509

16. Lawn JE, Blencowe H, Oza S, You D, Lee AC, Waiswa P, Lalli M, Bhutta Z, Barros AJ, Christian P, Mathers C, Cousens SN, Lancet Every Newborn Study Group (2014) Every newborn: progress, priorities, and potential beyond survival. Lancet 12:189-205. doi: 10.1016/S0140-6736(14)60496-7

17. Maisels MJ, Bhutani VK, Bogen D, Newman TB, Stark AR, Watchko JF (2009) Hyperbilirubinemia in the newborn infant $>$ or $=35$ weeks' gestation: an update with clarifications. Pediatrics 124:1193-8. doi:10.1542/peds. 2009-0329

18. Maisels MJ, Kring E (2006) Transcutaneous bilirubin levels in first 96 hours in a normal newborn population of $\geq 35$ weeks gestation. Pediatrics 117:1169-1173. doi:10.1542/peds. 2005-0744

19. Mishra S, Chawla D, Agarwal R, Deorari AK, Paul VK (2010) Transcutaneous bilirubin levels in healthy term and late preterm
Indian neonates. Indian J Pediatr 77:45-50. doi:10.1007/s12098010-0007-3

20. Ota E, Ganchimeg T, Morisaki N, Vogel JP, Pileggi C, Ortiz-Panozo E, Souza JP, Mori R, WHO Multi-Country Survey on Maternal and Newborn Health Research Network (2014) Risk factors and adverse perinatal outcomes among term and preterm infants born small-for-gestational-age: secondary analyses of the WHO MultiCountry Survey on Maternal and Newborn Health. PLoS One 9: e105155. doi:10.1371/journal.pone.0105155

21. Sanpavat S, Nuchprayoon I, Smathakanee C, Hansuebsai R (2005) Nomogram for prediction of the risk of neonatal hyperbilirubinemia, using transcutaneous bilirubin. J Med Assoc Thai 88:1187-93

22. Setia S, Villaveces A, Dhillon P, Mueller BA (2002) Neonatal jaundice in Asian, white, and mixed-race infants. Arch Pediatr Adolesc Med 156:276-9

23. Slusher TM, Zipursky A, Bhutani VK (2011) A global need for affordable neonatal jaundice technologies. Semin Perinatol 35: 185-91. doi:10.1053/j.semperi.2011.02.014

24. Strickland SS (1993) Human nutrition in Mongolia: maternal mortality and rickets. Nomadic Peoples 33:231-239. http://cnp. nonuniv.ox.ac.uk/pdf/NP_journal_back_issues/Human_nutrition in Mongolia S Strickland.pdf Accessed 7 March 7, 2015

25. Varvarigou A, Fouzas S, Skylogianni E, Mantagou L, Bougioukou D, Mantagos S (2009) Transcutaneous bilirubin nomogram for prediction of significant neonatal hyperbilirubinemia. Pediatrics 124: 1052-9. doi:10.1542/peds. 2008-2322

26. Yamamoto LG, Killeen J, French GM (2012) Transcutaneous bilirubin measurement methods in neonates and its utility for Emergency Department use. Pediatr Emer Care 28:380-384

27. Yang WC, Zhao LL, Li YC, Chen CH, Chang YJ, Fu YC, Wu HP (2013) Bodyweight loss in predicting neonatal hyperbilirubinemia 72 hours after birth in term newborn infants. BMC Pediatr 21;13: 145. doi:10.1186/1471-2431-13-145

28. Yu ZB, Dong XY, Han SP, Chen YL, Qiu YF, Sha L, Sun Q, Guo XR (2011) Transcutaneous bilirubin nomogram for predicting neonatal hyperbilirubinemia in healthy term and late-preterm Chinese infants. Eur J Pediatr 170:185-91. doi:10.1007/s00431-010-1281-9 